\title{
Influencia de la calidad microbiológica del agua de consumo humano en la enteroparasitosis de los pobladores del sector linderos bajo - Jaén
}

\section{Influence of the microbiological quality of the water for human consumption in the enteroparasitosis of the inhabitants of the low - Jaén sector}

\author{
Huamuro Edinson ${ }^{1}$, Rivera Christian ${ }^{2}$, Torres Luz ${ }^{3}$, Carbajal Luis ${ }^{4}$
}

\section{RESUMEN}

Se determinó la influencia de la calidad microbiológica del agua de consumo humano en la entero parasitosis de los pobladores del sector Linderos Bajo - Jaén, Provincia de Jaén, Cajamarca, Perú. Para ello se realizaron análisis copro parasitológicos, uno por individuo de 76 familias seleccionadas, como también se analizaron muestras de agua de las redes de distribución de las viviendas para el análisis microbiológico, utilizando el método del número más probable. En el laboratorio, cada muestra de heces fue procesada por la técnica directa (solución salina fisiológica y lugol). La frecuencia de parasitados fue de 77.6 \% y se hallaron 4 especies de enteroparásitos; Giardia lamblia con $37.29 \%$ y Blastocystis hominis con 35.59\%. Así mismo, del total de muestras de agua analizadas microbiológicamente (recuento de mesófilos, coliformes totales, fecales y parasitológicos), el 61.5\% corresponden a muestras microbiológicamente aptas para consumo humano y $38.46 \%$ corresponde a muestras no aptas para el consumo humano; no se encontraron parásitos en las muestras de agua analizadas. Se concluye que no existió influencia de la calidad microbiológica del agua de consumo humano en la enteroparásitosis de los pobladores del sector Linderos Bajo - Jaén, por no haberse evidenciado parásitos en las muestras de agua.

Palabras claves: Calidad Microbiológica, Agua de consumo humano, Enteroparásitos.

\begin{abstract}
The influence of the microbiological quality of the water for human consumption on the gut-parasites of the inhabitants of the Linderos Bajo - Jaén sector, Jaén Province, Cajamarca, Peru was determined. For this, faecal parasitological analyses were carried out, one per individual of 76 selected families, as well as water samples from the distribution networks of the houses for the microbiological analysis, using the most probable number method. In the laboratory, each stool sample was processed by the direct technique (physiological saline solution and lugol). The frequency of parasitized was $77.6 \%$ and 4 species of gut-parasites were found; Giardia lamblia with $37.29 \%$ and Blastocystis hominis with $35.59 \%$. Likewise, of the total water samples analyzed microbiologically (count of mesophiles, total, faecal and parasitological coliforms), 61.5\% correspond to microbiologically suitable samples for human consumption and $38.46 \%$ correspond to samples unfit for human consumption; no parasites were found in the water samples analyzed. It is concluded that there was no influence of the microbiological quality of the water for human consumption in the gut-parasites of the inhabitants of the Linderos Bajo - Jaén sector because there were no parasites in the water samples.
\end{abstract}

Keywords: Microbiological quality, Water for human consumption, gut-parasites

\footnotetext{
${ }^{1}$ Bachiller en Tecnología Médica - Tecnólogo Médico - Universidad Nacional de Jaén - Responsable de Laboratorio de Biología. Correo electrónico: edihuamuro93@gmail.com

${ }^{2}$ Bachiller en Ciencias Biológicas- Biólogo Microbiólogo - Maestro en Biotecnología - Maestro en la Universidad Nacional de Jaén - Docente de Bacteriología xyian26@hotmail.com

${ }^{3}$ Bachiller en Ciencias Biológicas - Bióloga Microbióloga - Doctora en Ciencias Ambientales - Universidad Nacional de Jaén - Docente de Microbiología

${ }^{4}$ Bachiller en Ciencias Contables - Doctor En Gestión Pública y Gobernabilidad - Universidad Nacional de Jaén - Docente.
} 


\section{INTRODUCCIÓN}

A nivel mundial, el $80 \%$ de las enfermedades infecciosas y parasitarias gastrointestinales se deben al uso y consumo de agua insalubre, la falta de higiene y la carencia o el mal funcionamiento de los servicios sanitarios son algunas de las razones por las que la diarrea continúa representando un importante problema de salud en países en desarrollo, siendo el agua y los alimentos contaminados se los principales vehículos involucrados en la transmisión de bacterias, virus y parásitos que crecen en el tracto intestinal y abandonan el cuerpo por las heces ( R I E S G O D E E N F E R M E D A D E S TRANSMITIDAS POR EL AGUA EN ZONAS RURALES, s.f.).

En América Latina las enfermedades gastrointestinales de origen microbiano representan uno de los mayores costos asociados a la degradación ambiental, especialmente por su impacto en la mortalidad y morbilidad infantil. La transmisión de enfermedades ocurre a través de la contaminación de fuentes de agua, en redes de distribución de aguas mal operadas y precariamente mantenidas, y en la recontaminación intradomiciliaria, resultando en diarreas crónicas, disentería amebianas y otras dolencias graves incluyendo cólera, hepatitis y fiebre tifoidea. En las zonas rurales, más pobres de la población, las enfermedades gastrointestinales son responsables por el 7,3\% de la mortalidad infantil (Mejía \& Bernardo, 2012).

En el Perú, 2017, el 89,4\% de las personas tiene acceso a agua por red pública, de los cuales el $84,1 \%$ tiene acceso a agua por red pública dentro de la vivienda, el 3,9\% tiene acceso fuera de la vivienda pero dentro de la edificación y el 1,3\% tiene acceso por pilón de uso público, el acceso y la calidad de los servicios de agua y desagüe han mostrado disminuir el riesgo de enfermedades diarreicas principalmente de origen parasitario ((INEI), Instituto Nacional de Estadística e Informática, 2018)

Según estudios realizados en Cajamarca la parasitosis intestinal, es un problema de salud pública de alta incidencia en los niños, y constituyen una de las diez primeras causas de morbilidad y de mortalidad causado por las enfermedades infecciosas intestinales debido a la alta ruralidad de la región cajamarquina es favorable, desde el punto de vista epidemiológico, socioeconómico y ecológico, para que los niños adquieran infecciones parasitarias con mayor frecuencia el desarrolló del estudio incluyó a 41 niños menores de 12 años que se les entregó envases para la recolecta de muestras fecales para el diagnóstico, del total de niños, 35 presentaron algún tipo de parasitosis intestinal y 22 de ellos presentaban al menos un parásito potencialmente patógeno, siendo Giardia lamblia el más frecuente; 19 presentaron multiparasitismo con un máximo de 4 especies por hospedero siendo la asociación Giardia lamblia y Endolimax nana la más frecuente, esto se debe a cuyas viviendas tienen pisos de tierra, carecen de servicio de desagüe y entre los que a menudo beben agua sin hervir (Rodríguez, 2010).

El sector Linderos se ubica en la provincia de Jaén, Altitud de 729 msnm, Latitud: entre los $5^{\circ} 15^{\prime \prime}$ y los $6^{\circ} 4^{\prime \prime}$ de latitud Sur; y entre los 78 $33^{\prime \prime}$ y los 79 $38^{\prime \prime}$ de longitud Oeste y además el agua que consume la población de Linderos no es una agua tratada y que cumpla las normas sanitaras de la DIGESA; ante los descrito es importante que los pobladores y autoridades se informen, y hagan conciencia sobre cómo mejorar la calidad de agua que consumen y así prevenir enfermedades como las entero parasitosis.

Esta investigación nació a partir del siguiente problema: La influencia microbiológica en la entero parasitosis con el consumo de agua en la población de Linderos Bajo- Jaén. Se justifica por la buena o mala calidad de agua que consume la población es un impacto que general en la salud pública, afectando la salud de la gente que la consume.- Investigaciones en distinto lugares de la región Cajamarca el agua no cumple con estándares de buena calidad, por eso se decidió ver la influencia de calidad microbiológica de agua en relación a la entero parasitosis en el caserío de Linderos Bajo - Jaén, esto puede afectar la salud y bienestar en niños.

En esta investigación se propuso determinar la influencia de la calidad microbiológica del agua de consumo humano sobre la entero parasitosis de los pobladores del sector Linderos Bajo - Jaén, 2019, estimar la frecuencia de entero parasitosis en pobladores del sector, estimar la frecuencia de los entero parásitos encontrados en las muestras de heces de los pobladores del sector, estimar la frecuencia de muestras de agua microbiológicamente aptas para consumo humano en el sector y determinar la calidad microbiológica del agua para consumo humano según el recuento de bacterias heterótrofas mesófilas viables, coliformes totales, coliformes fecales y parasitológicos en muestras de agua de consumo humano en el sector de Linderos Bajo - Jaén, 2019.

\section{MATERIALES Y MÉTODOS}

La investigación propuesta se enmarcó en una investigación de tipo descriptivo observacional simple y transversal porque se analizó las muestras de agua y muestras de heces de la población en un solo momento. 
La muestra fue 76 usuarios (considerando que los miembros de cada familia hacen el uso del servicio) que fueron escogidos por el muestreo aleatorio simple de 157 usuarios, a los cuales se les realizó análisis parasitológico en materia fecal de sus familias.

Así mismo se analizó 13 muestras de agua para determinar la calidad microbiológica del agua que consumen según (coliformes totales, coliformes fecales, aerobios mesófilos, parasitología).

\section{EXÁMENES PARASITOLÓGICOS}

En un portaobjetos se colocará separadamente una gota de solución salina fisiológica y otra de Lugol. Se tomó una pequeña porción de material fecal y se realizan suspensiones con ambas soluciones, se cubre con laminillas cubreobjetos y se observa al microscopio con objetivo 10X y luego 40X.

\section{M É T O D O M I C R O B I O L Ó G I C O Y PARASITOLÓGICO}

Para la determinación de coliformes totales y termo tolerantes, se utilizará el método del número más probable (NMP).

Para el recuento de bacterias Aerobias Mesófilas Viables, método de recuento en placa método de concentración por sedimentación en agua y examen seriado de heces.

\section{ANÁLISIS DE DATOS}

Para el procesamiento de los datos se aplicó el programa Excel para desarrollar las tablas y gráficas para su análisis e interpretación.

\section{RESULTADOS}

En las muestras de heces examinadas a los 76 usuarios y sus familias se encontró $77.6 \%$ de enteroparasitosis

Figura 1. Frecuencia de enteroparásitosis en pobladores del sector Linderos Bajo- Jaén, 2019

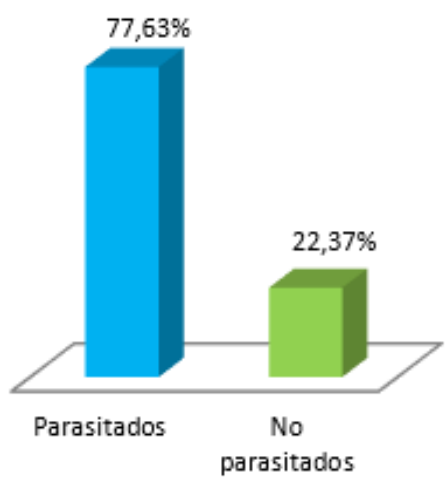

Figura 2. Especies de entero parasitosis encontrados en pobladores del sector Linderos Bajo - Jaén, 2019

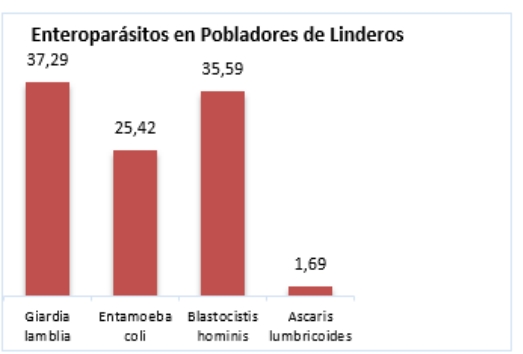

Se hallaron cuatro especies distintas de entero parásitos, entre protozoarios y helmintos, de ellas, Giardia lamblia con 37.29\% y Blastocystis hominis $25.42 \%$ fueron los protozoarios con mayor frecuencia (Tabla 2).

Así mismo del total de muestras de agua analizadas el $61.5 \%$ corresponden a muestras microbiológicamente aptas para consumo humano y $38.46 \%$ corresponde a muestras no aptas para el consumo humano en la población de Linderos Bajo.

Finalmente se encontró en el pozo 3, un total de mesófilos viables que asciende a $1280 \mathrm{UFC} / \mathrm{ml}$. Mientras que en el pozo 2 se halló 920 NMP/100 ml de coliformes totales y, en los pozos 2 y 4 se identificó $11 \mathrm{NMP} / 100 \mathrm{ml}$ de coliformes fecales, además no se evidencio la presencia de parásitos.

Figura 3. Frecuencia de muestras de agua microbiológicamente aptas para consumo humano en el sector Linderos Bajo - Jaén, 2019.

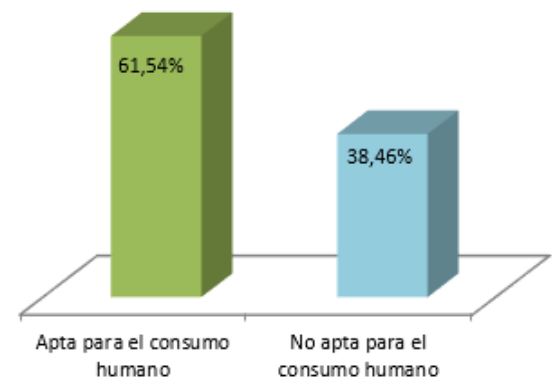

Figura 4. Calidad microbiológica del agua de consumo humano según aerobios mesófilos, coliformes totales, fecales y parásitos, en el sector Linderos Bajo-Jaén, 2019

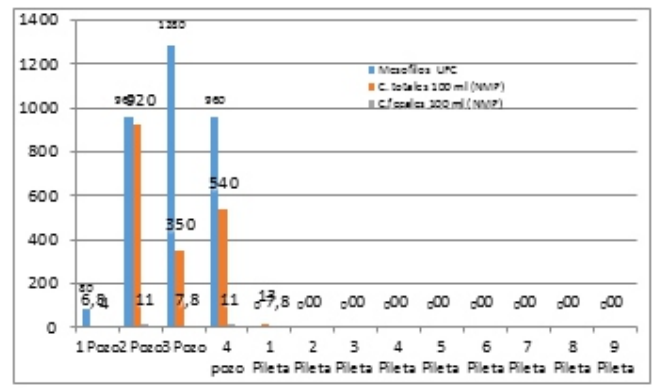




\section{DISCUSIÓN}

En la presente investigación se determinó la frecuencia de enteroparasitosis en los pobladores de Lindero Bajo, encontrándose en un $77.6 \%$. Resultados similares a los obtenidos por (Rivera et a1.), quienes encontraron un 62,5\% de enteroparásitos, lo que se debería al clima caluroso y lluvioso de la zona que condiciona la presencia de un suelo arcilloso, siempre

húmedo, óptimo para la evolución, mantenimiento y propagación de los helmintos y protozoarios, presente en la ciudad de Jaén. Además de las deficientes medidas higiénicas y de salubridad pública, como la inadecuada disposición de excretas, preparación de los alimentos, entre otros (Ibáñez, Jara, \& Guerra., 2004).

Así mismo, los enteroparásitos que se encontraron con mayor frecuencia fueron Giardia lamblia en un $37.29 \%$ y Blastocystis hominis en $35.59 \%$. Al respecto, (Rivera et al.), reportaron a Giardia lamblia en un 37.7\% y Entamoeba coli 30.4\%, Valdivia y cols., reportaron a Giardia lamblia 18.5 $\%$ y Entamoeba coli $58 \%$ como los parásitos más frecuentes. Esto se debería, a que dichos parásitos son de fácil diseminación, debido a que su principal forma de transmisión es por ingestión de agua y alimentos contaminados, lo que se relaciona con las malas condiciones de saneamiento ambiental presentes en la zona como la deficiente eliminación de basura, riegos con la subsecuente contaminación de alimentos (Botero \& Restrepo, 2012).

Por otra parte, en este estudio se evaluó la calidad microbiológica del agua extraída de pozos que se encuentran en el sector Linderos Bajo, considerando la cantidad de mesófilos, coliformes totales, fecales y parásitos como parámetros para su medición. Obteniendo que, el $38,46 \%$ de las muestras observadas no se encuentran aptas para el consumo humano, debido a que superan los límites máximos permisibles de los parámetros microbiológicos, según el Decreto Supremo No. 031-2010-SA, ya que el recuento de bacterias heterótrofas, no debe ser mayor a $500 \mathrm{UFC} / \mathrm{ml}$. Así mismo el recuento de coliformes totales, fecales y parasitológicos debería ser de $0 \mathrm{NMP} / 100 \mathrm{ml}$ y 0 org./1 respectivamente, condiciones microbiológicas que no se cumplen, esto se explicaría a que los sistema de captación de agua, desagüe y alcantarillado no tienen adecuadas condiciones de higiene, siendo un ambiente favorable para el desarrollo de parásitos y otros microorganismos.

\section{CONCLUSIONES}

La frecuencia de enteroparasitosis en los pobladores del caserío Linderos Bajo, Jaén fue de 77.6\%.

Los enteroparásitos más frecuentes son Giardia lamblia con $37.29 \% \quad y$ Blastocystis hominis con $35.59 \%$.

Se evidenció que el $61.5 \%$ corresponden a muestras microbiológicamente aptas para consumo humano y $38.46 \%$ corresponde a muestras no aptas para el consumo humano.

Se encontró un total de mesófilos viables que asciende a $1280 \mathrm{UFC} / \mathrm{ml}$. Mientras $920 \mathrm{NMP} / 100 \mathrm{ml}$ de coliformes totales y $11 \mathrm{NMP} / 100 \mathrm{ml}$ de coliformes fecales y 0 parásitos.

Se determinó que no existe influencia de la calidad microbiológica del agua de consumo humano en la enteroparasitosis de los pobladores del sector Linderos Bajo - Jaén, por no haberse evidenciado parásitos en las muestras de agua analizadas.

\section{REFERENCIAS BIBLIOGRÁFICAS}

Agua potable para comunidades rurales, reusó y tratamientos avanzados de aguas residuales domésticas. [Online] Acceso 12 de noviembre $\mathrm{de} 2018$. D is ponible e n: http://www.bvsde.paho.org/bvsacd/cd57/ries go.

Mejía, Bernardo. Agua potable y saneamiento en américa latina y el caribe. 6th ed. Cap., editor. Panamá; 2012.

(INEI), Instituto Nacional de Estadística e Informática. INEI. [Online]. 2018. Acceso 5 de julio de 2018. Disponible en: www.inei.gob.pe.

Rodríguez C. Parasitosis intestinales y factores socio sanitarios en niños del área rural del distrito de Los Baños del Inca, Cajamarca. Revista Médica Herediana. 2010;21(2).

Ibáñez, Jara, Guerra. Prevalencia del Enteroparasitismo en escolares de comunidades nativas del Alto Marañón, Amazonas, Perú. Scielo Perú. 2004; 21(3).

Botero, Restrepo. Parasitología humana Colombia: corporación para la investigación; 2012. 